\title{
A database of high-impact weather events in Greece: a descriptive impact analysis for the period 2001-2011
}

\author{
K. Papagiannaki, K. Lagouvardos, and V. Kotroni \\ Institute of Environmental Research and Sustainable Development, National Observatory of Athens, Athens, Greece \\ Correspondence to: K. Papagiannaki (katpap@noa.gr) \\ Received: 23 July 2012 - Published in Nat. Hazards Earth Syst. Sci. Discuss.: - \\ Revised: 6 February 2013 - Accepted: 11 February 2013 - Published: 20 March 2013
}

\begin{abstract}
This paper introduces the development of a database of high-impact weather events that occurred in Greece since 2001. The selected events are related to the occurrence of floods, flash floods, hail, snow/frost, tornados, windstorms, heat waves and lightning with adverse consequences (excluding those related to agriculture). The database includes, among others, the geographical distribution of the recorded events, relevant meteorological data, a brief description of the induced impacts and references in the press. This paper further offers an extensive analysis of the temporal and spatial distribution of high-impact weather events for the period 2001-2011, taking into account the intensity of weather conditions and the consequent impact on the society. Analysis of the monthly distribution of highimpact weather events showed that they are more frequent during October and November. More than 80 people lost their lives, half of which due to flash floods. In what concerns the spatial distribution of high-impact weather events, among the 51 prefectures of the country, Attica, Thessaloniki, Elia and Halkidiki were the most frequently affected areas, mainly by flash floods. Significant was also the share of tornados in Elia, of windstorms in Attica, of lightning and hail events in Halkidiki and of snow/frost events in Thessaloniki.
\end{abstract}

\section{Introduction}

Disasters associated to natural hazards have been gaining increasing scientific interest in the last decades due to their significant socioeconomic and environmental impacts. Besides, the excessive growth of financial losses the insurance industry is confronted with during the last $30 \mathrm{yr}$ implies an upward trend of natural disasters (MunichRe, 2012). Additionally, recent literature addresses concerns over the impact climate change may have on the frequency and magnitude of extreme weather events (IPCC, 2012). A possible future increase in weather extremes and their adverse consequences requires effective disaster risk management and adaptation to climate change. In that context, systematic monitoring and accounting for disaster losses help to enhance the arguments for coordinated disaster risk mitigation (UNISDR, 2011) and to provide the necessary tools for policy-making. Events due to natural hazards are separated into four basic groups: the geophysical events that concern mostly earthquakes, the meteorological events and specifically storms, the hydrological events with flooding and mass movement and the climatic events that include extreme temperatures, drought and wildfires (MunichRe, 2012). Even though earthquakes are among the most catastrophic events and may cause a large number of fatalities, they are not considered in the present analysis, which focuses strictly on weather related events.

The last decade, scientists have addressed the social and socioeconomic aspects of disasters associated with weather parameters, to improve our understanding of the interrelations between hazards, vulnerability and risk perception (Messner and Meyer, 2006). Llasat et al. (2008) examine the intrinsic hazards of major floods in Catalonia in northeast Spain, for years 2005 and 2006, and assess the vulnerability of the affected areas, as defined by population growth and density. Following the concept of modern techniques on natural disaster risk evaluation, Lastoria et al. (2006) present a historical database of major floods that took place in Italy since 1951, structured to include data and information regarding geographical location, amount of precipitation, number of casualties and restoration funds. The analysis shows a 
considerable societal impact attributed to severe flood events, while the archiving of relevant data was intended to support risk mitigation policy measures. In the same line, Llasat et al. (2009b) develop a press articles database on natural disasters in Catalonia in order to study the development of social risk perception and its implication in risk management. The authors examine all types of high-impact weather events of the period 1982-2007, through a wide set of press articles related criteria. The analysis of the relationship between scientific data for severe weather events, their harmful results and press coverage indicates changes in communities' risk perception and acceptance of effective protection measures.

The continuous monitoring of weather-related damages is considered of great importance by both the scientific and end-user communities worldwide, as well as at European and national level. Collection of data and information concerning the impact of weather events at local or cross-border level are very useful in both disaster risk management and long-term statistical study of weather-related disasters. In 2006, the European Severe Storms Laboratory (ESSL) addressed the need for a homogeneous data format for reporting disastrous weather events, aiming at producing basic and statistical climatology and hazard assessment in European level. The ESSL recently proceeded to developing the first pan-European database of severe thunderstorm reports (Dotzek et al., 2009), available "on-line" to the public and designed to cover all local severe storms with a high level of meteorological detail. Large flood events are also the subject of the Dartmouth Flood Observatory of the University of Colorado, which created a global active archive filled with information derived from news, governmental, instrumental and remote-sensing sources. The database provides geographical data, the duration of the event, the exact cause of the flood and an estimated severity index based on the recurrence interval (http://floodobservatory.colorado.edu/ Archives/index.html). One of the most important and open to the public databases, with wide geographical coverage, is the EM-DAT database (http://www.emdat.be), which is operated by the Centre for Research on the Epidemiology of Disasters (CRED) at Leuven University (l'Université catholique de Louvain) in Belgium and focuses on very large events with significant losses (more than 10 fatalities and over 100 people affected), thus, excluding events with smaller losses, the overall cost of which can be also significant. Similar is the NatCatService database (MunichRe, 2012), which, though, applies lower criteria for the entry of an event and provides economic damage costs and mortality rates (Kron et al., 2012). The NatCatService is accessible to the public, but information about small events is not available.

Greece experiences a variety of weather events that are frequently followed by adverse consequences on the socioeconomic activity. Nevertheless, the recording and study of high-impact weather events and their negative consequences so far is partial, covering only certain time periods and regions of the country (Papanikolaou and Diakakis, 2011) and focusing mostly on flash floods, which are responsible for major damages and a large number of fatalities. Stathis (2004), in his paper on the relation of extreme rainfall and floods in Greece, presents 150 intense flood events in the country for the period 1980-2002 and builds flood risk maps based on the geographical distribution of the events. The findings of this study show an increasing risk due to human related factors, such as urbanism and lack of flood-preventing measures. According to Ganoulis (2003), the growth of population in urban, coastal and riverside areas has led to a remarkable increase in the economic impacts of flash floods in Greece during the last decades. Following the Directive 2007/60/EC on the assessment and management of flood risks, Floros (2009) formulates a single database record for flood events, analyses four large events of the last $50 \mathrm{yr}$ in Attica Prefecture and produces flood hazard and risk maps. In their study on preliminary flood risk assessment for the city of Athens, Kandilioti and Makropoulos (2012) apply a GISbased multi-criteria methodology and generate flood risk and methodological complexity maps on the basis of hydrometeorological, morphological, socioeconomic and infrastructure related parameters.

The present paper introduces the development of a database of high-impact weather events in Greece, which are associated with various impact intensities. The database includes events related with floods, flash floods, hail, snow/frost, tornados, windstorms, heat waves and lightning. In addition, the database provides relevant meteorological data, classification of the events based on their weather intensity and impact intensity, geographical distribution of the events, as well as a brief description and references in the press. It covers all the high-impact weather events that occurred since 2001, while it is continuously updated to provide systematic monitoring and the foundation for future long-term impact analysis. Furthermore, the database is available online for educational and scientific purposes (http://www.meteo.gr/weather_cases.asp). Thus, the present database aims not only to incorporate and systematically record previous and future high-impact weather events in Greece, but also to make this information available for future long-term societal impact analysis. Moreover, this study, based on the developed database, offers an extensive analysis of the temporal and spatial distribution of high-impact weather events for the period 2001-2011, taking into account the weather and impact intensity of each event.

The following sections present the methodological aspects related to the construction of the database, the sources of data and information used, as well as the analysis of the highimpact weather events in Greece during the last decade, followed by discussion and concluding remarks. 


\section{Methodology}

The methodological aspects of the database development, use and application on societal impact analysis, concern the collection of past data with regard to high-impact weather events, the categorisation of the events according to their weather and impact intensity and the design of the database application.

\subsection{Data and sources}

Past data describing the weather events and their impact on society are drawn from the monthly bulletins redacted at the National Observatory of Athens (NOA), as well as from several news agencies and newspapers, available in hard-copy or online. As for the meteorological observations, the databases of the network of surface meteorological stations operated by NOA and by the Hellenic National Meteorological Service are used.

The database covers events associated with various weather-related phenomena, namely floods, flash floods, hail, tornados, windstorms, heat waves, snow/frost and lightning or a combination of them. Specifically, each event may concern more than one type of phenomena, as well as more than one region of the country. It is usual, for example, to observe both flash flood and hail in the same day and to record negative consequences from both events. Namely, for the construction of the database, each event is associated with the weather-related phenomena that took place and also with its duration, which is connected to the occurrence of losses and is measured in days.

It should be noticed that landslides related to weather are not considered separately in the database, as suggested by the disaster category classification developed by CRED and MunichRe (Below et al., 2009), but rather as part of the damages induced during a high-impact weather event. The reason is that landslides constitute a cumulative effect of several factors, such as various and extended weather related processes the duration of which is not clear, human factors and morphology, and cannot be treated as isolated events. Additionally, droughts are not included in the database, since in Greece they do not associate it with direct societal impacts. Extended dry periods indirectly affect the water resources and, depending on the season, the sector of agriculture. However, the present analysis does not take into consideration weather events that caused exclusively agricultural losses, since they constitute a special category with thousands of cases involved requiring, thus, a different methodological approach. It is obvious that the high frequency of these cases would mask the importance of events with different types of damages, while issues regarding the sensitivity of agricultural production to weather invoke a separate impact intensity classification. The socio-economic impact of weather events in Greek agriculture is actually the subject of the authors' future work.
The examined high-impact weather events are geographically allocated over the Greek territory at prefecture level (51 in total). Further information required, apart from the geographical and temporal one, concern the kind of induced societal impact, the number and causes of human fatalities, if any, the estimate of impact and weather intensity, relevant meteorological data and press news sources. A shortcoming related to the database, is that it does not yet include economic losses caused by the high-impact weather events, because of the difficulty in collecting the specific data from the various governmental services and insurance companies implicated in the procedure of monetary compensations due to natural disasters.

\subsection{Classification of high-impact weather events}

High-impact weather, as defined by the Meteorological Service of Canada (Sills, 2009) "is weather that can result in significant impacts on safety, property and/or socioeconomic activity". More analytically, weather impact refers to adverse effects on society, such as transportation and network disruption, damages on infrastructure, buildings and vehicles, human fatalities and economic losses. Impact analysis, therefore, involves a clear identification of the criteria set to evaluate and classify the magnitude of events. In the recent literature, Llasat et al. $(2008,2010)$ discern three main categories of flood events, taking into account the type of impacts along with the hydrological profile of the flood. In the present analysis, two different classifications of high-impact weather events have been introduced, the first one based on the intensity of weather conditions and the second one based on the impact intensity, namely the type and magnitude of the overall impact of the event. It is, thus, possible to analyse events with a focus on the magnitude of impacts and to observe the relation between weather and impact intensity. More specifically, three levels of impact intensity $(I)$ and weather intensity $(W)$ are considered in the analysis and the categorisation shown in Table 1 has been adopted.

Impact intensity levels relate to the type and magnitude of the reported damages caused by each event, without though considering the actual economic damage costs, which are not available in the present analysis. Impacts considered are associated with human losses or injuries, with every-day activities and services, (e.g., transportation and network disruption, school closures), with damages in property (e.g., buildings and cars), with damages in infrastructure (e.g., electricity and telecommunication networks). The magnitude of impacts is further related to the number of prefectures affected, in order to standardise the classification of both the events identified during the studied period and also the forthcoming events, on the basis of objective criteria. Therefore, small-scale problems, limited to 1 out of the 51 prefectures of the country, correspond to the lowest level of impact intensity (I1); large-scale problems that affect 2-4 prefectures, or one of the most populated cities of the country, as well 
Table 1. Categories of impact and weather intensity.

\begin{tabular}{|c|c|c|}
\hline \multicolumn{3}{|l|}{ Categories of impact and weather intensity } \\
\hline Impact intensity $-I 1$ & Impact intensity $-I 2$ & Impact intensity $-I 3$ \\
\hline $\begin{array}{l}\text { Minor effects, such as small-scale trans- } \\
\text { port and network disruption, light dam- } \\
\text { ages in infrastructure and limited num- } \\
\text { ber of damaged buildings. } \\
\text { Only } 1 \text { prefecture affected. }\end{array}$ & $\begin{array}{l}\text { Serious effects, such as large-scale transport } \\
\text { disruption, significant building, car and infras- } \\
\text { tructure damages, fire caused by lightning. } \\
2-4 \text { prefectures affected, or one of the most } \\
\text { populated cities of the country* affected. }\end{array}$ & $\begin{array}{l}\text { Human losses and/or widespread dam- } \\
\text { ages in } 5 \text { or more prefectures af- } \\
\text { fected and/or long duration problems } \\
\text { (e.g., transport disruption for more than } \\
3 \text { days). }\end{array}$ \\
\hline Weather intensity $-W 1$ & Weather intensity $-W 2$ & Weather intensity $-W 3$ \\
\hline $\begin{array}{l}\text { Precipitation less than } 60 \mathrm{~mm} \text { within } \\
24 \mathrm{~h} \text {, or less than } 15 \mathrm{~mm} \text { in } 1 \mathrm{~h} \text {. } \\
\text { Wind gusts less than } 20 \mathrm{~m} \mathrm{~s}^{-1} \text {. }\end{array}$ & $\begin{array}{l}\text { Precipitation between } 60 \mathrm{~mm} \text { and } 100 \mathrm{~mm} \\
\text { within } 24 \mathrm{~h} \text {, or } 15-25 \mathrm{~mm} \text { within } 1 \mathrm{~h} . \\
\text { Wind gusts between } 20 \mathrm{~m} \mathrm{~s}^{-1} \text { and } 27 \mathrm{~m} \mathrm{~s}^{-1} \text {. } \\
\text { Minimum temperature between }-5^{\circ} \mathrm{C} \text { and } \\
-10^{\circ} \mathrm{C} \text {. } \\
\text { Maximum temperature between } 40^{\circ} \mathrm{C} \text { and } \\
42^{\circ} \mathrm{C} \text {. }\end{array}$ & $\begin{array}{l}\text { Precipitation more than } 100 \mathrm{~mm} \text { within } \\
24 \mathrm{~h} \text {, or more than } 25 \mathrm{~mm} \text { within } 1 \mathrm{~h} \text {. } \\
\text { Wind gusts exceeding } 27 \mathrm{~m} \mathrm{~s}^{-1} \text {. } \\
\text { Minimum temperature less than } \\
-10^{\circ} \mathrm{C} \text {. } \\
\text { Maximum temperature more than } \\
42^{\circ} \mathrm{C} \text {. } \\
\text { Tornados. } \\
\text { Heavy snowfall. }\end{array}$ \\
\hline
\end{tabular}

* Cities with more than 100000 inhabitants: Athens, Thessaloniki, Patras, Heraclion, Larissa, Volos.

as certified events of fire from lightning strikes, correspond to the middle level of impact intensity (I2); human fatalities and/or widespread damages over at least 5 prefectures and/or events that cause problems in every-day activities (e.g., transport disruption due to snow) for more than 3 days, correspond to the highest level of impact intensity (I3).

Weather intensity levels are also described in Table 1. The network of the meteorological stations used in the present work for the identification and characterisation of the events has expanded considerably during the last decade and, thus, the available data do not permit to derive statistical/climatological thresholds of extremes. The station databases have variable record lengths and the geographical coverage of the oldest stations is poor in order to derive general objective weather intensity levels. Thus, a subjective choice of thresholds has been made (Table 1) that is believed to not jeopardise the results that follow. Nevertheless for the definition of the weather intensity levels, the analysis of Amaro et al. (2010), who made a study of the social impact of hazardous meteorological events in the frame of MEDEX (MEDiterranean EXperiment on cyclones that produce high-impact weather in the Mediterranean) project, has been also considered. Based on these criteria, an event derives its weather intensity if at least one of the thresholds and/or phenomenon of the relevant category has been exceeded and/or observed, respectively.

\subsection{Database applications}

All information regarding the high-impact weather events that occurred in Greece since 2001 have been stored in an

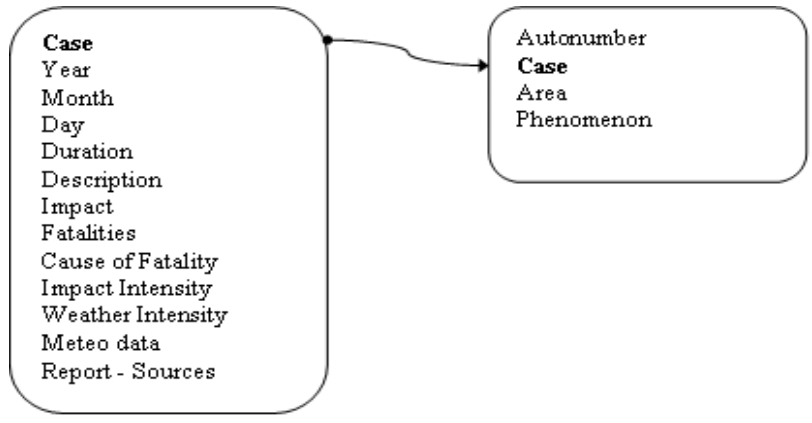

Fig. 1. Design of the relational Access database.

Access database, to facilitate exploitation and dissemination of the statistical data and results. Two basic linked Tables have been created for that purpose, the relationship of which ("one-to-many") is shown in Fig. 1, where each case corresponds to one high-impact weather event that may relate to multiple weather-related phenomena and to the affected prefectures.

The automated menu of the database consists of a search engine on the basis of key-parameters, such as the date of each event, the impact and weather intensity and the type of weather-related phenomena that occurred during each event, as well as of several summary reports and charts displaying, among others, the number and causes of fatalities and the distribution of events by year, month and prefecture.

The outputs constitute important informative material with regard to the characteristics and the evolution of high-impact 


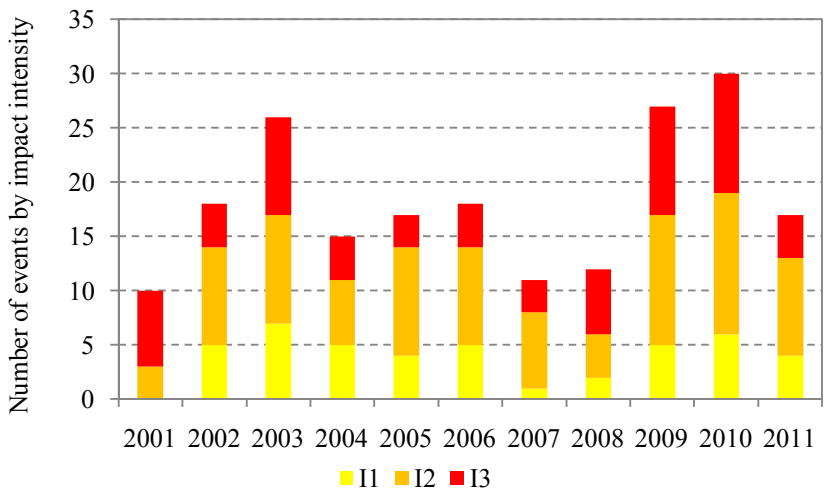

Fig. 2. Annual distribution of high-impact weather events by impact intensity, for the period 2001-2011.

weather events in Greece over the past decade. Furthermore, ongoing systematic recording shall permit in the future a long-term societal impact analysis with high quality data leading, thus, to validate statistical conclusions. In fact, the lack of long-term data and the uncertainty regarding the quality of existing historical data constitute two major obstacles to reach conclusions on the patterns of high-impact weather events (Kron et al., 2012; Easterling et al., 2000). Equally in this study, the more the search is expanded backward, the greater the possibility for missing events or part of the overall impact of a certain event. The main reason is the lack of systematic records of high-impact weather events and their consequences. Additionally, limited coverage of past events and completeness issues relatively to the data provided by the news services, are likely to be associated with risk perception (Llasat et al., 2009a), which is rather growing lately due to the increasing concern on natural disasters, their environmental and economic dimensions and the implication of urbanism to the magnitude of damaging effects.

\section{Impact analysis}

\subsection{Temporal distribution}

The database contains 201 high-impact weather events that occurred in Greece during the period 2001-2011. As explained in Sect. 2, each event may concern several types of the examined weather-related phenomena, which, in turn, may have affected several prefectures.

Figures 2-3 present the temporal (annual and monthly) distribution of the high-impact weather events, taking into account the estimated impact intensity of each one. The annual distribution shows considerable variations with a peak in 2010, a year during which 30 events were recorded. This variability, however, cannot be statistically assessed, considering the short time period examined. Accordingly, there is strong year-to-year variability in the number of events by

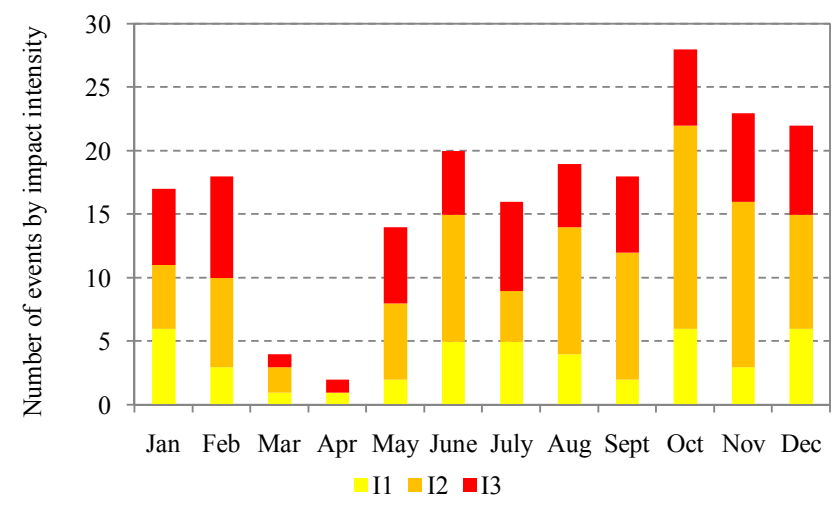

Fig. 3. Monthly distribution of high-impact weather events by impact intensity, for the period 2001-2011.

impact intensity, although there is a noticeable numerical predominance of events with high impact intensity (categories $I 2$ and I3) over the low impact ones (category I1). This is partly related to the low share of events with $W 1$ weather intensity, although impacts of $I 1$ intensity are produced by $W 2$ and $W 3$ events as well, but to a smaller extent as it will be seen later (Fig. 11). Of the total number of reported events, $32 \%$ caused $I 3$ impacts, $46 \%$ caused $I 2$ impacts and $22 \%$ caused impacts of $I 1$ intensity.

High-impact weather events are more frequent in October and November. This is expected, taking into account the climatology of the Eastern Mediterranean Basin, which is characterised by high precipitation amounts during autumn (Katsanos et al., 2007; Lolis et al., 1999) that may produce severe floods (Lagouvardos et al., 1996). Indeed, flash floods account for the $64 \%$ of total events that occurred during October and November. Somewhat lower is the frequency of events during the winter months, while spring months and especially March and April were the months with the fewest cases of high-impact weather events. As it concerns the summer months, during which a significant number of events occurred, the thunderstorms that develop are localised, but they can be violent, with high rain rates and important lightning activity (Petrova et al., 2009; Mazarakis et al., 2008).

One quarter of total reported events and $82 \%$ of total $I 3$ events are associated with human fatalities. Monthly analysis of these cases (Fig. 4) indicates a high fatality rate attributed to summer months, followed by May and September. The seven fatalities in July are almost all related to lightning activity (5 out of 7). Overall, 84 people lost their lives during the period 2001-2011 due to weather events. More specifically, weather related human fatalities were mostly victims of flash flood events and lightning and much less of windstorm and tornado (Fig. 5). Figure 6 shows the monthly distribution of human fatalities from lightning strikes. A total of 20 deaths have been reported over the past decade, the 19 of which occurred between May and September. All lightning events, except two, took place in central and especially in 


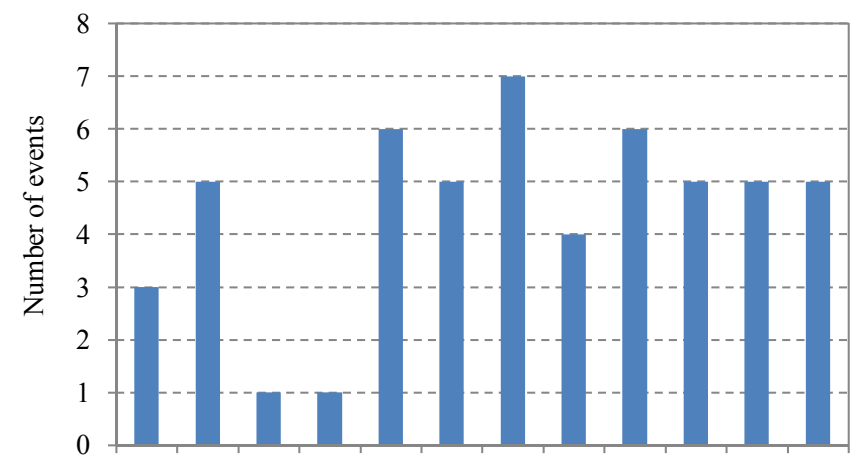

Jan Feb Mar Apr May June July Aug Sept Oct Nov Dec

Fig. 4. Monthly distribution of weather events with human fatalities, for the period 2001-2011.

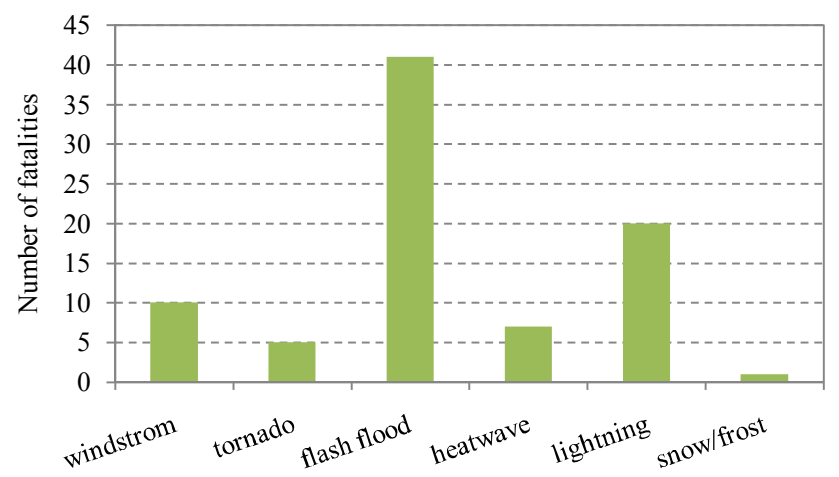

Fig. 5. Number of fatalities by type of weather-related phenomenon, for the period 2001-2011.

northern Greece. Indeed, a recent analysis of lightning activity (based on data from a lightning detection network) during summer in Greece revealed that thunderstorms affect mainly northern Greece during this period of the year (Mazarakis et al., 2008), while southern Greece and the islands experience limited thunderstorm activity.

The distribution of the weather-related phenomena by their type is illustrated in Fig. 7, for the entire period examined. As explained previously (Sect. 2) a case of high-impact weather event may concern more than one type of weather-related phenomena (for example occurrence of both windstorms and flash flood). Flash floods have been reported approximately in 130 out of the 201 events. Obviously, flash flood constitutes the most common weather-related phenomenon with damages in the Greek territory. Significantly lower are the percentages of the other phenomena, while flood and heat wave come last, representing $4 \%$ and $1 \%$, respectively, of the total damaging events. Indeed, according to Llasat et al. (2010), during the period 2000-2006, flash floods have been found to be the most dangerous meteorological hazards in the entire Mediterranean area.

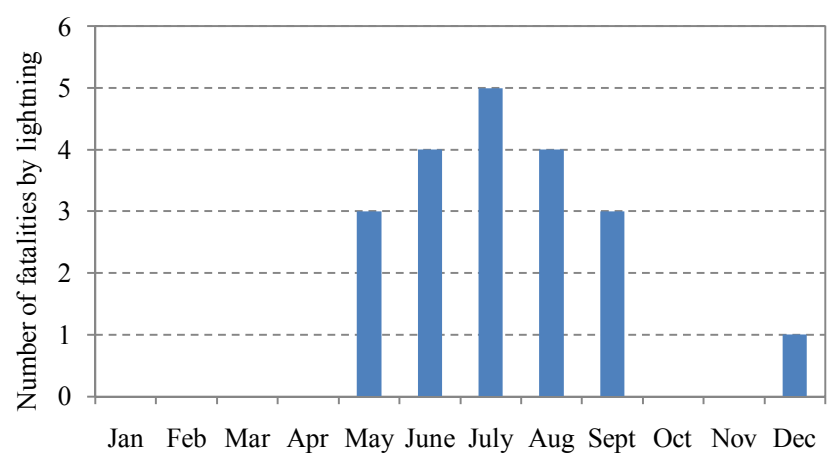

Fig. 6. Number of fatalities from lightning strikes, for the period 2001-2011.

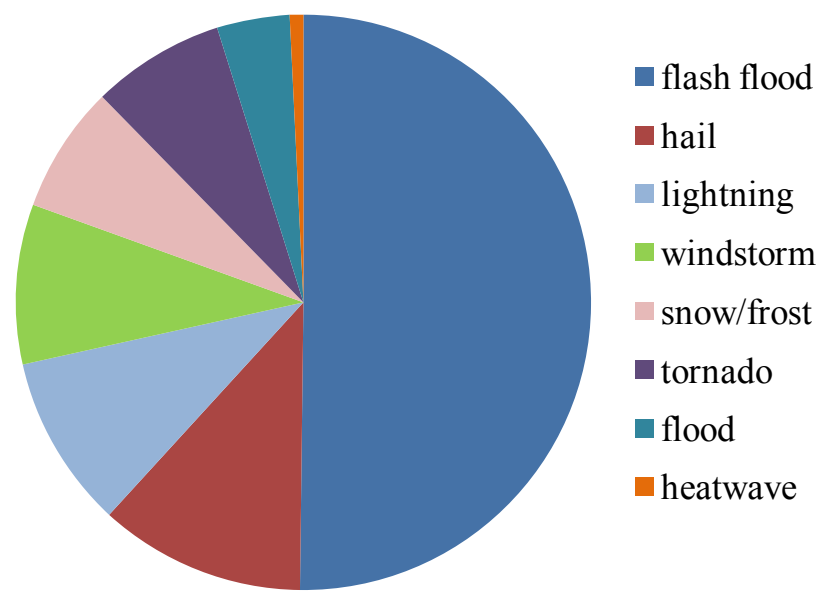

Fig. 7. Distribution (\%) of the total number of weather-related phenomena by type (2001-2011).

It should be noted that Fig. 7 does not take into account the extent to which each weather-related phenomenon affects the country. This information is provided in Fig. 8 that shows the average number of prefectures affected by each type of weather-related phenomenon, with the aim to provide an indicator of their average impact range, in what concerns the period 2001-2011. Heat waves are excluded from Fig. 8 because of the small number of relevant events with certified impacts (only two heat waves with specific impacts have been reported). The average impact range of snow/frost (4.5 prefectures) exceeds by far the respective ones of the other types, which is though expected from the nature of the weather phenomenon. Besides, snow alone, or in combination with frost, usually lasts long and creates accumulated and rolling problems, such as road network cut off and power outage, that affect many regions (Lagouvardos et al., 2007). A medium impact range is estimated for flash flood, flood and windstorm, which negatively affect $2-2.5$ prefectures by event on average, while more localised phenomena 


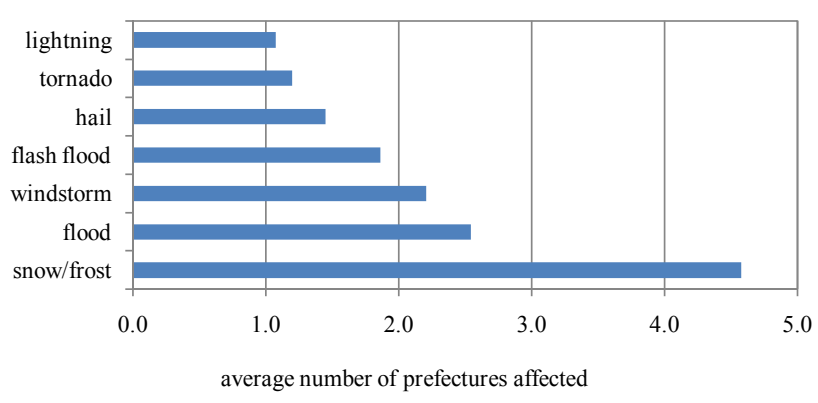

Fig. 8. Average impact range for each type of weather-related phenomenon.

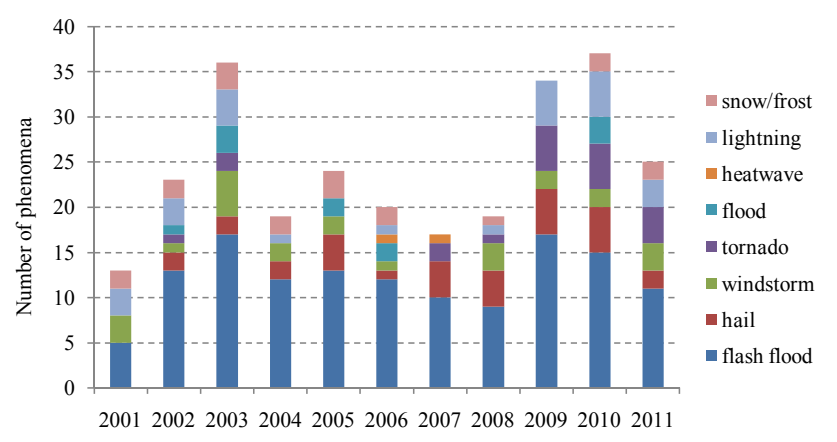

Fig. 9. Annual distribution of weather-related phenomena by type, for the period 2001-2011.

such as hail, tornado and lightning have an impact range of $1-1.5$ prefectures.

Figure 9 depicts the annual distribution of weather-related phenomena. Frequencies of all phenomena vary considerably from year to year, without exhibiting an overall increasing or decreasing trend. Except from flash flood events, the rest have been occurring irregularly, while flash flood ranks as the most frequent type in all years examined. At this point heat waves deserve a comment. Indeed, warm spells that result in temperatures of the order of $40^{\circ} \mathrm{C}$ are not unusual for Greece (Prezerakos, 1989). Although heat wave could be considered as a $W 3$ event, the degree of preparedness has increased the last decade and thus the impacts have reduced considerably. That is why the number of heat waves included in the database is quite low ( 2 in total). During the studied period, the June 2007 event was the most important one when the maximum temperature in Athens reached $44.8^{\circ} \mathrm{C}$ (the absolute maximum temperature since 1897). This heat wave resulted in 5 deaths, while the same heat wave affected Italy, the Balkans and Cyprus where 42 deaths in total were reported (Kotroni et al., 2011).

Figure 10 compares the types of weather-related phenomena with regards to their impact intensity. Heat waves are excluded from this distribution, because of the small number of relevant events, like previously mentioned. As it concerns the cases of lightning, it is the only phenomenon, among the

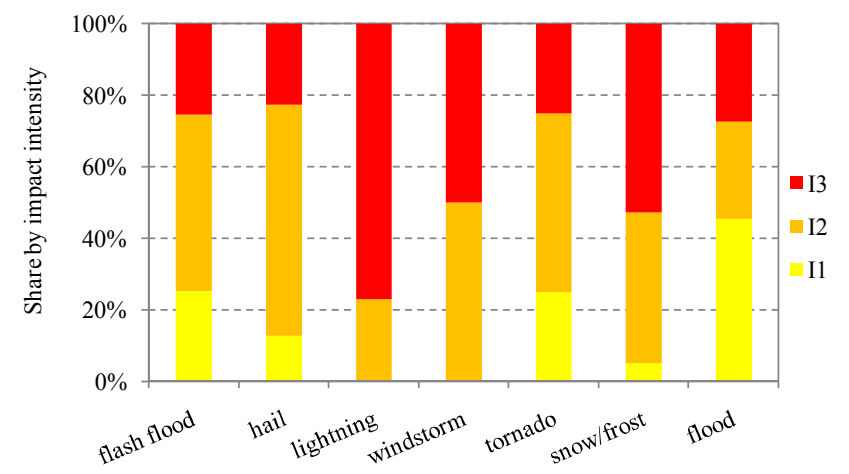

Fig. 10. Distribution (\%) of weather-related phenomena by type of phenomenon and impact intensity (2001-2011).

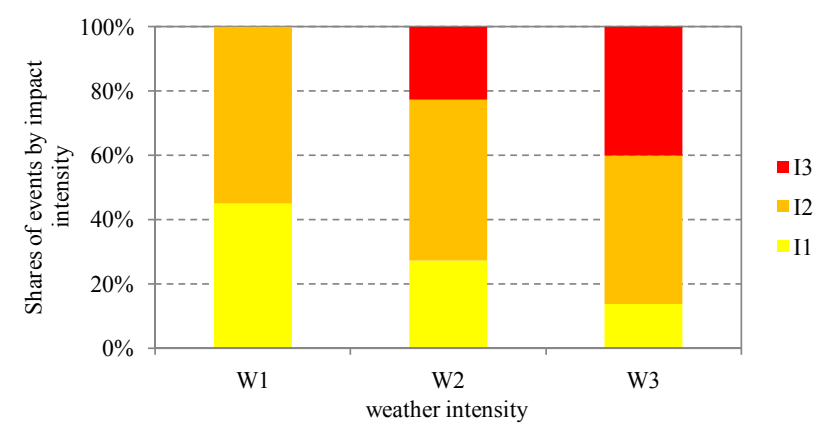

Fig. 11. Distribution (\%) of events (excluding those with fatalities due to lightning) based on weather and impact intensity (20012011).

ones described in Fig. 10, which causes no less than serious damages and specifically loss of human life, that is $I 3 \mathrm{im}-$ pact intensity, or fire, which associates with $I 2$ impact intensity, following the criteria presented in Table 1 . Windstorm and snow/frost are involved with events that produced about $50 \%$ damages of $I 3$ impact intensity and almost no $I 1 \mathrm{im}-$ pact. Flash floods, tornados and hail, are associated mostly with events of $I 2$ impact intensity and much less of $I 1$ and $I 3$ intensity, while flood is associated mainly with $I 1$ events.

Figure 11 illustrates the distribution of high-impact weather events based on both impact and weather intensity. The combined results can be seen as a rough indicator of the sensitivity of the society to weather severity. Events with lightning casualties are excluded from Fig. 11 to avoid misconception of results, since these events, by definition of the criteria (Table 1), form a special combination of the lowest weather intensity $(W 1)$ and the highest impact intensity (I3) and no other combination could apply. As expected, higher weather intensities (W2 and W3) brought about mostly higher impact intensities ( $I 2$ and $I 3$, respectively). As it concerns the $W 1$ events, with the exception of lightning events with fatalities, half of them relate to $I 1 \mathrm{im}-$ pact intensity and another half with $I 2$ impact intensity. The 


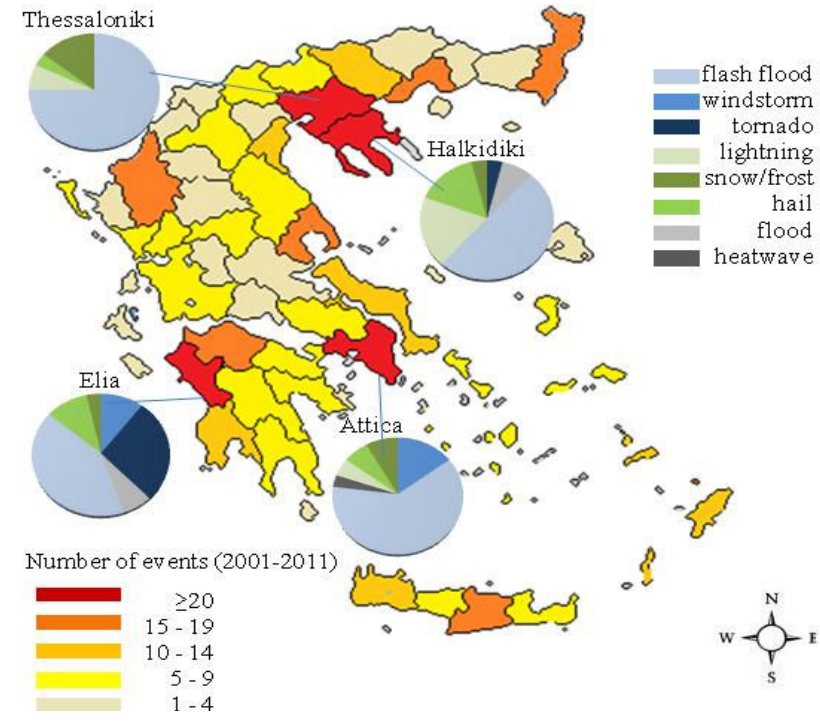

Fig. 12. Frequency of high-impact weather events in Greece by prefecture, between 2001 and 2011. Distribution by phenomenon for the most affected areas.

share of $W 1$ events is generally low (17\%), while over half of the events belong to the category $W 2$ and another $30 \%$ to the category $W 3$.

\subsection{Spatial distribution}

In order to further analyse the sensitivity of the Greek territory to intense weather conditions, a spatial distribution of high-impact weather events that occurred between 2001 and 2011 by prefecture is captured in Fig. 12. Specifically, the following picture informs us of the number of events that occurred to each prefecture. For presentation purposes the events have been grouped in five ranges $(1-4,5-9,10$ 14, 15-19, 220). Attica, Thessaloniki, Elia and Halkidiki were the most frequently affected areas, with 51, 27, 26 and 25 recorded events, respectively. Namely, approximately half of the high-impact events that occurred in the studied period affected at least one of these 4 regions, where the $47 \%$ of the Greek population lives.

Attica, which is the capital of Greece, holds the $34 \%$ of the total population and is the most affected region in Greece. Due to the high population density and intense economic activity, Attica constitutes a particularly vulnerable area to a variety of weather phenomena. Vulnerability to natural hazards increases further with the extended deforestation and urbanisation of this area. Indicative is the fact that, according to the present impact analysis, $50 \%$ of the events with $W 3$ weather intensity, that affected Attica among others, produced very adverse effects, of $I 3$ impact intensity in the area.

The second largest city is Thessaloniki, with $10 \%$ of the total population, while the prefectures of Elia and Halkidiki hold only $2 \%$ and $1 \%$ of the total population, respectively.
Flash flood was the main weather-related phenomenon with catastrophic consequences in both Attica and Thessaloniki, representing $62 \%$ and $71 \%$ of total events, respectively. Additionally, $50 \%$ of total damaging weather-related phenomena in Halkidiki and $40 \%$ in Elia were flash floods. Interestingly, according to Stathis (2004), three of the above mentioned prefectures, namely Attica, Halkidiki and Elia, showed high vulnerability to flash flood hazards in the period 1980-2002 as well.

The second most frequent phenomenon in each of the top 4 regions is windstorm in Attica, snow/frost in Thessaloniki, tornado in Elia and lightning activity in Halkidiki. Especially as it concerns the tornados, Sioutas (2011), who made a systematic investigation of tornados and waterspouts in Greece for the period 2000-2009, found that the probability of tornado occurrence for each of the Greek prefectures showed highest values for Kerkyra island and Elia in western Greece.

Approximately one fifth of the events that affected Attica and Thessaloniki, and one fourth of the events that occurred in Halkidiki belong to $I 3$ category of impact intensity. Among the top 4 regions, Elia exhibited the highest share of $I 2$ events $(85 \%)$ and the lowest share of $I 3$ events $(4 \%)$. The largest part of the country, specifically 19 out of 51 prefectures, is characterised by low frequencies of damaging events (5-9 events in the period 2001-2011). Another 16 prefectures were affected less than 5 times in the past decade, most of which are inland areas. On the other hand, all regions with high frequencies are located in the coastal zone of the country, which tends to be more heavily populated and, thus, more vulnerable to weather-related hazards compared to inland areas. This finding is in line with the conclusion of Ganoulis (2003) who associated the remarkable increase in the economic impacts of flash floods in Greece with the growth of population in urban, coastal and riverside areas.

\section{Concluding remarks}

The present paper introduced a database of high-impact weather events in Greece that combines meteorological data and descriptive information regarding the induced impact on society. The database concerns events recorded since 2001, including those with small, but not negligible impact, in order to cover a wide range of impact intensity categories. The studied high-impact weather events were associated with various weather-related phenomena, namely floods, flash floods, hail, tornados, windstorms, heat waves, snow/frost and lightning. This paper also presented an analysis of the temporal and spatial distribution of high-impact weather events, for the period 2001-2011, which have been classified according to the weather and impact intensity. Thus, it is possible to focus on the analysis of impact intensity and also to analyse impact intensity in comparison to weather intensity. The different levels of impact intensity are based on the magnitude of the weather related consequences and the number of areas 
affected. For that, geographical distribution of events is made at prefectural level.

The annual distribution of high-impact weather events recorded in Greece in the period 2001-2011 showed considerable variations with a peak in 2010. The frequencies of events by impact intensity also vary to an important degree from year to year, while the percentage of events having very high impact intensity (I3) ranges from $18 \%$ to $70 \%$. October and November exhibited the highest frequencies of events. Overall, 84 people lost their lives during the one quarter of total events recorded in the past decade. Half of these fatalities are attributed to flash flood events, while lightning caused 20 deaths that were recorded almost exclusively between May and September.

Half of the recorded weather-related phenomena were flash floods, which constitute the most frequent type of the examined phenomena throughout the period 2001-2011. Flash flood associates by $55 \%$ with events of $I 2$ impact intensity and by $26 \%$ with events of $I 3$ impact intensity. In general, with the exception of lightning events with human fatalities, which are by definition $W 1-I 3$ events, the pattern of the relation between weather and impact intensity indicates that events classified into a specific weather intensity category, most probably associate with impact intensity of the same level.

In what concerns the spatial distribution of high-impact weather events, among the 51 prefectures of the country, Attica, Thessaloniki, Elia and Halkidiki were the most frequently affected areas, mainly by flash floods. Moreover, the frequency of tornados in Elia, of windstorms in Attica, of lightning and hail events in Halkidiki and of snow/frost events in Thessaloniki was high.

The design and maintenance of the present database constitute an initiative of the atmospheric modelling group of the National Observatory of Athens, with the intention to provide a tool for societal impact analysis of weather events in Greece. What is very important, apart from the originality of the database, is that it is available "on-line" for educative and scientific purposes and it is continuously updated to provide systematic monitoring and the required data for future long-term statistical analysis. However, limitations regarding the present research exist and associate mostly with the lack of economic cost data, which would certainly offer the possibility to define more objective thresholds for impact intensity and, thus, to develop an integrated socioeconomic impact analysis. It is in the future plans of the authors to further explore the possibility to obtain such data, which is, however, depending on the coordination of the various governmental services and insurance companies implicated in the procedure of compensations related to natural disasters. Furthermore, the authors are planning to investigate the socio-economic impact of weather events in Greek agriculture, which accounts for significant losses related to crop production and livestock.
Acknowledgements. The authors acknowledge the Hellenic National Meteorological Service for the provision of some meteorological data used in this paper, as well as the daily newspaper "ETHNOS" for the provided access to their archives. The authors also acknowledge the important contribution of amateur meteorologists who provided valuable reports of events and especially Christos Petropoulos for sharing his personal records of highimpact weather events. We would finally like to thank Angelika Wirtz and the anonymous referees for their helpful suggestions that considerably improved the manuscript.

Edited by: M.-C. Llasat

Reviewed by: A. Wirtz and two anonymous referees

\section{References}

Amaro, J., Gayà, M., Aran, M., and Llasat, M. C.: Preliminary results of the Social Impact Research Group of MEDEX: the request database (2000-2002) of two Meteorological Services, Nat. Hazards Earth Syst. Sci., 10, 2643-2652, doi:10.5194/nhess-10-2643-2010, 2010.

Below, R., Wirtz, A., and, Guha-Sapir, D.: Disaster category classification and peril terminology for operational purposes, Annex II., available at: http://emdat.be (last access: February 2013), 2009.

Dotzek, N., Groenemeijer, P., Feuerstein, B., and Holzer, A. M.: Overview of ESSL's severe convective storms research using the European Severe Weather Database ESWD, Atmos. Res., 93, 575-586, 2009.

Easterling, D. R., Evans, J. L., Groisman, P. Ya., Karl, T. R., Kunkel, K. E., and Ambenje, P.: Observed Variability and Trends in Extreme Climate Events: A Brief Review, B. Am. Meteorol. Soc., 81, 417-425, 2000.

Floros, I.: Developing a database for recording flood incidents, MSc Thesis, Department of Water Resources and Environmental Engineering, School of Civil Engineering, National Technical University of Athens, 2009 (in Greek).

Ganoulis, J.: Risk-based floodplain management: A case study from Greece, Int. J. River Basin Manage., 1, 41-47, 2003.

IPCC: Managing the Risks of Extreme Events and Disasters to Advance Climate Change Adaptation (SREX), 2012.

Kandilioti, G. and Makropoulos, C.: Preliminary flood risk assessment: the case of Athens, Nat. Hazards, 61, 441-468, 2012.

Katsanos, D., Lagouvardos, K., Kotroni, V., and Argiriou, A.: Combined analysis of rainfall and lightning data produced by mesoscale systems in the Central and Eastern Mediterranean, Atmos. Res., 83 55-63, 2007.

Kotroni, V., Lagouvardos, K., and Retalis, A.: The heat wave of June 2007 in Athens, Greece - Part 2: Modeling study and sensitivity experiments, Atmos. Res., 100, 1-11, doi:10.1016/j.atmosres.2010.12.007, 2011.

Kron, W., Steuer, M., Löw, P., and Wirtz, A.: How to deal properly with a natural catastrophe database - analysis of flood losses, Nat. Hazards Earth Syst. Sci., 12, 535-550, doi:10.5194/nhess12-535-2012, 2012.

Lagouvardos, K., Kotroni, V., Dobricic, S., Nickovic, S., and Kallos, G.: On the storm of 21-22 October 1994 over Greece: Observations and model results, J. Geophys. Res.-Atmos., 101, 2621726226, 1996. 
Lagouvardos, K., Kotroni, V., and Defer, E.: The 21-22 January 2004 explosive cyclogenesis over the Aegean Sea: Observations and model analysis, Q. J. Roy. Meteorol. Soc., 133, 1519-1531, 2007.

Lastoria, B., Simonetti, M. R., Casaioli, M., Mariani, S., and Monacelli, G.: Socio-economic impacts of major floods in Italy from 1951 to 2003, Adv. Geosci., 7, 223-229, doi:10.5194/adgeo-7223-2006, 2006.

Llasat, M. C., López, L., Barnolas, M., and Llasat-Botija, M.: Flashfloods in Catalonia: the social perception in a context of changing vulnerability, Adv. Geosci., 17, 63-70, doi:10.5194/adgeo17-63-2008, 2008.

Llasat, M. C., Llasat-Botija, M., Barnolas, M., López, L., and Altava-Ortiz, V.: An analysis of the evolution of hydrometeorological extremes in newspapers: the case of Catalonia, 1982-2006, Nat. Hazards Earth Syst. Sci., 9, 1201-1212, doi:10.5194/nhess-9-1201-2009, 2009a.

Llasat, M. C., Llasat-Botija, M., and López, L.: A press database on natural risks and its application in the study of floods in Northeastern Spain, Nat. Hazards Earth Syst. Sci., 9, 2049-2061, doi:10.5194/nhess-9-2049-2009, 2009b.

Llasat, M. C., Llasat-Botija, M., Prat, M. A., Porcú, F., Price, C., Mugnai, A., Lagouvardos, K., Kotroni, V., Katsanos, D., Michaelides, S., Yair, Y., Savvidou, K., and Nicolaides, K.: High-impact floods and flash floods in Mediterranean countries: the FLASH preliminary database, Adv. Geosci., 23, 47-55, doi:10.5194/adgeo-23-47-2010, 2010.

Lolis, C. J., Bartzokas, A., and Metaxas, D. A.: Spatial covariability of the climatic parameters in the Greek area, Int. J. Climatol., 19, 185-196, 1999.
Mazarakis, N., Kotroni, V., Lagouvardos, K., and Argiriou, A. A.: Storms and Lightning Activity in Greece during the Warm Periods of 2003-2006, J. Appl. Meteorol. Climatol., 47 ,3089-3098, 2008.

Messner, F. and Meyer, V.: Flood damage, vulnerability and risk perception - challenges for flood damage research, Proceedings of the NATO Advanced Research on Flood Risk Management Hazards, Vulnerability and Mitigation Measures. Springer Editions, 2006.

MunichRe: available at: http://www.munichre.com/touch/ naturalhazards/en/natcatservice/default.aspx (last access: November 2012), 2012.

Papanikolaou, D. and Diakakis, M.: Changes in the intensity and distribution of natural disasters, Climate Change Impacts Study Committee, Bank of Greece, 2011.

Petrova, S., Mitzeva, R., Kotroni, V., Latham, J., and Peneva, E.: Analyses of summer lightning activity and precipitation in the Central and Eastern Mediterranean, Atmos. Res., 91, 453-458, 2009.

Prezerakos, N. G.: A contribution to the study of the extreme heatwave over the south Balkans in July 1987, Meteorol. Atmos. Phys., 41, 261-271, 1989.

Sills, D. M. L.,: On the msc forecasters forums and the future role of the human forecaster, B. Am. Meteorol. Soc., 90, 619, doi:10.1175/2008BAMS2657.1, 2009.

Sioutas, M. V.: A tornado and waterspout climatology for Greece, Atmos. Res., 100, 344-356, 2011.

Stathis, D.: Extreme rainfall-events and flood-genesis in Greece, 18 Oct 2004, 7PGC/HGS, 2004.

UNISDR: Global Assessment Report on Disaster Risk Reduction, 2011. 